\title{
ORAL HEALTH RELATED KNOWLEDGE AND ATTITUDE OF ANGANWADI WORKERS OF MANGALORE CITY, INDIA
}

\author{
A Shakya ${ }^{1 *}, \mathrm{ARa0}^{2}, \mathrm{R}_{\text {Shenoy }}{ }^{3}, \mathrm{M}_{\text {Shrestha }}{ }^{4}$ \\ ${ }^{1}$ Community Dentistry, College of Dental Sciences, Chitwan Medical College, Bharatpur-10, Chitwan, Nepal. \\ ${ }^{2}$ Public Health Dentistry, Manipal College of Dental Sciences, Mangalore, India. \\ ${ }^{3}$ Public Health Dentistry Manipal College of Dental Sciences, Mangalore, India. \\ ${ }^{4}$ Department of Oral Pathology, College of Dental Sciences, Chitwan Medical College, Bharatpur-10, Chitwan, Nepal. \\ *Correspondence to : Dr Ajay Shakya, College of Dental Sciences, Chitwan Medical College, Bharatpur-10, Chitwan, Nepal. \\ Email:drajayshakya@gmail.com
}

\begin{abstract}
Dental caries is a common childhood disease. Its prevalence can be reduced by integrating dental strategies into primary health care approach. Knowledge, attitude and practice of anganwadi workers in the subject of oral health is imperative in achieving this goal. This study was therefore conducted to assess the knowledge and attitude towards oral health among anganwadi workers of Mangalore city. A questionnaire study, using convenience samples was conducted among 159 anganwadi workers of Mangalore city. A close ended questionnaire consisting of 20 questions was used. Details of age and qualification were recorded. The data was analyzed using SPSS 11.5 . Only $45.9 \%$ of the anganwadi workers knew that dental caries was a disease, $57.2 \%$ knew that the best time to eat sweets was during meal time, $58.5 \%$ workers stated dentists as their source of oral health information. Almost all of the Anganwadi workers were positive towards the importance of oral health education and expressed their willingness to teach children how to brush properly and obliged to advise a child needing dental care to go to dentist. An anganwadi worker can be a vital link in the health care delivery system. There is a need to educate them on oral health in order to reach children at an early and receptive age. It is very important on the part of the health department to carry out effective programmes on oral health for anganwadi workers.
\end{abstract}

Key Words: Anganwadi, Caries, Knowledge, Prevention.

\section{INTRODUCTION}

Dental caries is a preventable disease. As the disease starts in early childhood with the eruption of the milk tooth, preventive strategies would be most effective if it is started on or before the time of eruption of milk tooth at about 6 months of age. ${ }^{1}$

The Primary Health Care approach has been advocated as the strategy to achieve health for all. ${ }^{2}$ Integrating dental strategies into this approach would require oral hygiene instruction, as part of general hygiene instruction, be carried out by community health workers, social workers and so on in addition to dental personnel. ${ }^{3}$

Anganwadi worker is community - based voluntary frontline worker of Integrated Child Development Services (ICDS) programme - India's response to the challenge of meeting the holistic needs of the children. ${ }^{4}$ Empowering anganwadi workers in oral health, and providing basic oral health awareness to the mothers through them is a feasible model for a country like India; where oral health is not a priority in the primary health care as yet. At the anganwadis, monthly meeting of mothers are held and these serve as platforms for health education. ${ }^{1}$

This study was therefore conducted to assess the knowledge and attitude towards oral health among anganwadi workers of Mangalore city and to correlate the knowledge and attitude with their age, academic qualification and years of experience.

\section{MATERIALS AND METHOD}

The study was carried out in Mangalore city, located in Dakshina Kannada district of Karnataka state, India. There are around 205 anganwadi workers in Mangalore city. Permission to conduct the survey was obtained from Child Development Project Office, Mangalore. Informed consent was also obtained from the individual subject. Convenience sampling technique was used. Those who were willing to participate were included in the study. For comparison, the study population was categorized on the basis of their age, educational qualification and years of experience.

On prefixed dates, the investigator visited the Child Development Project Office, where the anganwadi workers gathered for the monthly meetings. The purpose of the study was explained, and consent was obtained from the workers. A specially designed, close ended questionnaire in Kannada language consisting of 20 questions was used. Information regarding age, sex, qualification was also collected. The data collected were entered in the SPSS 


\section{5 and were further analyzed.}

\section{RESULTS}

A total 159 out of 205 anganwadi workers participated in the study. Their age ranged from 19 years to 56 years. Though the overall knowledge was high among anganwadi workers, the important findings were that only $45.9 \%$ of the anganwadi workers knew that dental caries was a disease, 93.7\% knew that bacteria was the cause of tooth decay, $57.2 \%$ knew that the best time to eat sweets was during meal time, and $88.1 \%$ reported that it was natural to lose teeth with increasing age. A total of $58.5 \%$ stated dentists as their source of oral health information. Other sources were newspapers (41.5\%), television $(40.3 \%)$, radio $(25.8 \%)$, physicians $(22 \%)$, magazines $(15.1 \%)$, others $(25.7 \%)$.

Comparisons between age groups and educational qualification for each question indicated no considerable differences. Almost all of the Anganwadi workers were positive towards the importance of oral health education. When asked for their opinion about educating people and children about dental health, almost all of them agreed that it helps in preventing dental disease. Majority of the anganwadi workers expressed their willingness to teach children how to brush properly and obliged to advise a child needing dental care to go to dentist.

\section{DISCUSSION}

Primary dental care is the way of achieving good oral health for the community. The most feasible and sustainable method to achieve this is through integration of oral healthcare in the existing primary healthcare activities, through training of community level workers. ${ }^{3}$

When enquired about their oral health related knowledge, majority (78.35\%) of them had good knowledge. Almost all of them had a favourable attitude towards oral health, as in an earlier study $(86.4 \%)$ by Pankaj et al. ${ }^{3}$

Though the study showed that anganwadi workers of Mangalore have awareness about dental health, nevertheless, a few knowledge gaps could be identified. The misconceptions regarding the causes of oral diseases were commonly found worldwide regardless geographical location and professional status. ${ }^{5}$ However, in this study, a huge majority of the participants considered bacteria as a cause of tooth decay which was similar $(96.7 \%)$ to a study by Mwangosi I.E.A.T., Nyandindi $\mathrm{U}^{4}$ and Wu IIM et al. ${ }^{6}$ Ironically, a larger percentage of respondents $(54.1 \%)$ didn't consider tooth decay as a disease.

Even though, knowledge on the relationship between sugar and tooth decay was high, this knowledge is also reportedly insufficient to influence behaviour. It may be easier to acquire knowledge than to apply it for avoiding the risks from frequent consumption of sugared snacks and drinks strictly for oral health reasons. ${ }^{5}$ Almost $70 \%$ of the participants stated that sugary food can cause tooth decay. A higher proportion (57.2\%) of participants knew about the correct time to eat sweets compared with participants in the Trinidad. ${ }^{7}$ This shows the incomplete oral health information among anganwadi workers who are already in-service as care takers of children.
It can be hypothesised that those caregivers who were more knowledgeable about the development of dental caries might also be more aware of the importance of oral health care and hence their children's oral condition. ${ }^{8}$ But in this study, sadly $35.2 \%$ of the anganwadi workers were unaware of the benefits of fluoridated toothpaste. This was in spite of the majority of anganwadi workers $(89.9 \%)$ saying that they considered tooth brushing to be a caries preventive measure. Therefore, the anganwadi workers need to be educated about the importance of fluoridated toothpaste which was similar (96.7\%) to a study by $\mathrm{Wu}$ I et al. ${ }^{6}$

Majority of them (88.1\%) considered that it was natural for people to lose teeth with increasing age, which indicated the need for more effective oral health education and promotion. When enquired about the knowledge about gum disease, a huge majority of respondents were aware of the cause, symptoms and detrimental effects and prevention of gum disease, which was similar to the result obtained in a study by Mwangosi I. E.A.T. and Nyandindi U. ${ }^{5}$ Majority of the participants, were equally aware of the harmful effects of tobacco on oral health.

When asked about their sources of oral health information, $93(58.5 \%)$ workers stated dentist as the source of oral health information, 66(41.5\%) stated newspaper, 64(40.3\%) stated television, 41(25.8\%) stated radio, 35(22\%) stated physician, $24(15.1 \%)$ stated magazines, 22(13.8\%) stated others and $19(11.9 \%)$ stated friends/neighbours as the source. This suggested that dentists played a major role in the information dissemination. However, only $22 \%$ of the participants of this study stated physicians as their sources of oral health information.

Table 1: Distribution Of Subjects According To Age

\begin{tabular}{|l|l|}
\hline Age (in years) & Subjects \\
\hline$\leq 30$ & $28(17.6 \%)$ \\
\hline $31-40$ & $63(39.6 \%)$ \\
\hline$\geq 41$ & $68(42.8 \%)$ \\
\hline Total & $159(100 \%)$ \\
\hline
\end{tabular}

Table 2: Distribution Of Subjects According To Educational Qualification

\begin{tabular}{|l|l|}
\hline Educational Qualification & Subjects \\
\hline Up to 10 & $86(54.1 \%)$ \\
\hline Pre university college & $58(36.47 \%)$ \\
\hline Degree & $15(9.43 \%)$ \\
\hline Total & $159(100 \%)$ \\
\hline
\end{tabular}


Table 3: Distribution Of Subjects According To Years Of Experience

\begin{tabular}{|l|l|}
\hline Years of experience & Subjects \\
\hline$\leq 5$ & $37(23.27 \%)$ \\
\hline $6-10$ & $26(16.36 \%)$ \\
\hline$\geq 11$ & $96(60.37 \%)$ \\
\hline Total & $159(100 \%)$ \\
\hline
\end{tabular}

\section{CONCLUSION}

The study suggests that the anganwadi workers in Mangalore might be regarded as moderately informed about oral health in some aspects but poorly informed in others. An anganwadi worker can be a vital link in the health care delivery system as he/she is in a position to provide a package of services to mothers and children. Since the topic of oral health is given a low priority in anganwadi workers training curriculum, there is a need to educate them on oral health in order to reach children at an early and receptive age.

Furthermore, the findings of the study suggest that it becomes imperative on the part of the health department to carry out effective programmes on oral health for anganwadi workers.

Educating the anganwadi workers will produce a ripple effect where the knowledge gets disseminated to the mother and to her family and then to the entire community.

\section{REFERENCES}

1. Nair MKC, Renjit M, Siju KE, Leena ML, George B, Suresh K G. Effectiveness of community oral health awareness programme. Indian Pediatrics 2009; 46:86-90.

2. Ndiokwelu E. Primary health care approach. Its relevance to oral health in Nigeria. Odontostomatol Trop. 2002 Sep;25(99):29-32.

3. Pankaj, Ankola A, Nagesh L, Hegde P. Knowledge, attitude and practices towards oral health among anganwadi workers of Belgaum city, Karnataka. Journal of the Indian Association of Public Health Dentistry. 2005; 5: 14-16.

4. Chattopadhyay D. Knowledge and skills of anganwadi workers in Hooghly district, West Bengal. Indian Journal of Community Medicine. 2004; 3: 117-118.

5. Mwangosi IEAT, Nyandindi U. Oral health related knowledge, behaviours, attitude and self-assessed status of primary school teachers in Tanzania. International Dental journal 2002; 52: 130-136.

6. Wu IIM, King NM, Tsai JSJ, Wong HM. The dental knowledge and attitudes of medical practitioners and caregivers of pre-school children in Macau. HK J Paediatr 2006; 11: 133-13.

7. Naidu RS., Davis L. Parents' views on factors influencing the dental health of Trinidadian pre-school children. Community Dental Health 2008; 25: 44-49.

8. Schwarz E, Lo ECM. Dental health knowledge and attitudes among the middle-aged and the elderly in Hong Kong. Community Dent Oral Epidemiol 1994; 22: 358-63. 